\title{
EFEITO DA PROFUNDIDADE DE TRABALHO DAS HASTES SULCADORAS DE UMA SEMEADORA-ADUBADORA NA PATINAGEM, NA FORCA DE TRAÇÃO E NO CONSUMO DE COMBUSTÍVEL DE UM TRATOR AGRÍCOLA
}

\author{
Effects of work operation depth of shanks in a seeder-fertilizer on slip, \\ traction force and fuel consumption of a tractor
}

\author{
Marcos Antonio Zambillo Palma ${ }^{1}$, Carlos Eduardo Silva Volpato ${ }^{2}$, Jackson Antonio Barbosa ${ }^{2}$, \\ Roger Toscan Spagnolo ${ }^{3}$, Murilo Machado de Barros ${ }^{4}$, Lidiane do Amaral Vilas Boas ${ }^{2}$
}

\begin{abstract}
RESUMO
A consolidação do sistema de semeadura direta trás grandes benefícios ao meio ambiente e, também, é notável a redução dos custos de produção devido a desnecessidade das operações como aração, subsolagem, escarificação e gradagem. Porém, nesse sistema se têm muitos problemas relacionados a compactação das camadas superficiais em função do tráfego de máquinas e a consorciação lavoura-pecuária. A solução encontrada pelos agricultores tem sido a substituição, na semeadora-adubadora, do sulcador disco duplo pela haste sulcadora que atua em profundidades superiores. O presente estudo teve como objetivo avaliar diferentes profundidades de trabalho da haste sulcadora, analisando o consumo de combustível, força de tração, índice de patinagem, potência na barra de tração, consumo específico de combustível e capacidade de campo teórica de um trator agrícola tracionando uma semeadora-adubadora em solo compactado pela integração lavoura-pecuária. Os tratamentos foram 100, 150, 200 e $250 \mathrm{~mm}$ de profundidade de trabalho da haste sulcadora, sendo os ensaios desenvolvidos no Departamento de Engenharia da Universidade Federal de Lavras, utilizando delineamento experimental de blocos, casualisados, composto por quatro tratamentos e três repetições. Dessa forma, conclui-se que o aumento da profundidade de trabalho da haste sulcadora em semeadoras-adubadoras de semeadura direta de milho em solos compactados ocorre o aumento no consumo de combustível, no índice de patinagem e no esforço de tração dos tratores agrícolas. Porém, quando a ponteira da haste sulcadora trabalhou posicionada $50 \mathrm{~mm}$ abaixo da camada mais compactada se teve reduções nos parâmetros força de tração e índice de patinagem, aumentando a capacidade de campo teórica.
\end{abstract}

Termos para indexação: Desempenho operacional, integração lavoura-pecuária, compactação do solo.

\begin{abstract}
The direct sowing system brings many benefits to the environment and also reduction in production costs, since operations such as plowing, subsoiling, chiseling and harrowing are unnecessary. However, there are many problems regarding compaction of the surface layers of soils due to machinery traffic and crop-livestock integration. The solution found by the farmers is the change of the double disc on the seeders for the shanks, which operate deeper. Therefore, this work aimed to evaluate different operation depths of the shank, analyzing the fuel consumption, traction force, slip index, draw-bar leverage, specific consumption of fuel and the theoretical field capacity of a tractor pulling a seeder-fertilizer over a soil compacted due to crop-livestock integration. The treatments were composed of four depths of the shanks, which were placed operating 100, 150, 200 and $250 \mathrm{~mm}$ deep. The experiments were carried out in randomized blocks design with four treatments and three repetitions at the Engineering Department of the Federal University of Lavras. The results showed that the increasing of operation depth of the shanks in a compacted soil increases the fuel consumption, the slip index and the leverage on the draw-bar. But when the shanks operated $50 \mathrm{~mm}$ beyond the most compacted layer, the traction force and the slip index have decreased, increasing the theoretical field capacity.
\end{abstract}

Index terms: Operational performance, crop-livestock integration, soil compaction.

(Recebido em 2 de fevereiro de 2010 a aprovado em 3 de setembro de 2010)

\section{INTRODUÇÃO}

O sistema de semeadura direta consiste num manejo do solo em que a palha e os restos vegetais são deixados na superfície do solo, sendo que se realiza o revolvimento do solo apenas no sulco em que são depositadas as sementes e os fertilizantes. Entre as vantagens agronômicas desse sistema se tem o controle da erosão, aumento da água armazenada no solo, redução da oscilação térmica, maior atividade biológica e maior teor de matéria orgânica (INSTITUTO AGRONÔMICO DE CAMPINAS-IAC, 2009).

Em áreas onde se realiza a integração lavourapecuária, a tensão da pisada dos bovinos sobre o solo

\footnotetext{
${ }^{1}$ Universidade Federal de Lavras/UFLA - Departamento de Engenharia - Cx. P. 3037 - 37200-000 - Lavras, MG - markospalma@gmail.com ${ }^{2}$ Universidade Federal de Lavras/UFLA - Departamento de Engenharia - Lavras, MG

3Universidade Federal de Pelotas - Faculdade de Agronomia Eliseu Maciel - Departamento de Engenharia Rural - Capão do Leão, RS ${ }^{4}$ Universidade Federal de Lavras/UFLA - Lavras, MG
} 
gera alterações na resistência a penetração mecânica do solo até as profundidades de $180 \mathrm{~mm}$ (Conte et al., 2007) a $200 \mathrm{~mm}$ (Lanzanova et al., 2007). De acordo com Kluthcouski et al. (2003), a integração pode ser feita pelo consórcio, sucessão ou ainda rotação de culturas anuais com forrageiras. Os objetivos da integração também são variados, sendo que na atividade pecuária vão desde a recuperação das pastagens até a produção forrageira na entressafra. Na exploração lavoureira, objetiva-se a quebra do ciclo de pragas, doenças e plantas daninhas, redução, via supressão física ou alelopática, de doenças das plantas cultivadas, agregando valores a ambos os sistemas de produção.

Stone \& Silveira (1999) verificaram que o sistema de semeadura direta resulta em maior compactação do solo do que o sistema de preparo de solo com arado de aiveca e o sistema com grade aradora. Streck et al. (2004) observaram, em um solo classificado como Argissolo Vermelho-Amarelo Distrófico arênico (Empresa Brasileira de Pesquisa Agropecuária-Embrapa, 1999) com textura superficial francoarenosa (camada de 0 a $30 \mathrm{~cm}$ ) e umidade gravimétrica de $15 \%$, que o tráfego de máquinas aumenta a densidade e a resistência à penetração do solo, reduzindo a porosidade total e a macroporosidade, mas não afetando significativamente a microporosidade. Além da utilização das hastes sulcadoras para a descompactação do solo, existem outros mecanismos como o cultivo de plantas de cobertura com sistema radicular pivotante. De acordo com Reinert et al. (2008), as plantas de cobertura, como o milho, apresentam bom desenvolvimento do sistema radicular em solos sem restrição, já em solos com densidades elevadas, o crescimento é consideravelmente menor, podendo se observar alterações morfológicas como engrossamento das raízes, desvios no crescimento vertical e a concentração na camada mais superficial do solo. Foloni et al. (2003) observaram, em um Argissolo Vermelho distrófico típico (Embrapa, 2006) com textura argilosa, que uma camada compactada, com resistência a penetração de $1,4 \mathrm{MPa}$ (umidade de 9 a 10\%), impede que o sistema radicular do milho atravesse e se desenvolva em profundidade. Também, existem indícios que o gesso agrícola (Sulfato de Cálcio Dihidratado - $\mathrm{CaSO}_{4} 2 \mathrm{H}_{2} \mathrm{O}$ ) pode alterar as características físicas do solo. Porém, Amaral et al. (2006) não constataram alterações no perfil de solo analisado após 12 meses da aplicação de $6 \mathrm{Mg} \mathrm{ha}^{-1}$ por hectare de gesso agrícola.

$\mathrm{O}$ uso do sistema de abertura de sulcos para deposição de fertilizante do tipo haste sulcadora aumenta as exigências de força de tração, o consumo de combustível (horário e específico) e o índice de patinagem, em relação ao sistema de abertura de sulcos do tipo discos duplo
(Santos et al., 2008), porém Mion \& Benez (2008) verificaram que a haste promove maior mobilização de solo. Silva \& Benez (2005) observaram que semeadoras-adubadoras equipadas com haste sulcadora, podem demandar 97,4\% mais força na barra de tração do que se fossem equipadas com sulcador tipo disco duplo.

Fernandes et al. (2008), avaliando o consumo energético de diferentes operações agrícolas mecanizadas, concluíram que os sistemas com menos operações por hectare obtiveram menor consumo de combustível, destacando a semeadura direta, seguida pelo cultivo mínimo com gradagem leve, vibro escarificador e o preparo convencional, que entre os sistemas estudados teve o pior desempenho.

Com o presente trabalho, objetivou-se avaliar consumo de combustível, força de tração, índice de patinagem, potência na barra de tração, consumo específico de combustível e capacidade de campo teórica de em um trator agrícola, desenvolvendo a tração de uma semeadoraadubadora equipada com hastes sulcadoras destinadas a semeadura direta de milho em solos compactado pela integração lavoura-pecuária.

\section{MATERIAL E MÉTODOS}

A pesquisa foi desenvolvida na Universidade Federal de Lavras - UFLA - situada no município de Lavras, MG. A localização geográfica da área experimental foi definida entre as coordenadas $21^{0} 13$ ' 50 ' latitude sul e 44 $57^{\prime}$ '52' longitude oeste a uma altitude de 943 metros. Nessa região, o clima se caracteriza por temperatura média anual de $19,4^{\circ} \mathrm{C}$ e precipitação total anual média de 1530 mm concentrada, principalmente, no período de outubro a março (clima classificado como Cwa.).

De acordo com o Departamento de Solos da UFLA, o solo da área experimental foi classificado como Latossolo Vermelho Distroférrico típico argiloso (LVdf), em que os resultados da análise granulométrica na camada de 0-300 mm apresentaram os valores médios de 0,16, 0,18 e $0,66 \mathrm{~kg} \mathrm{~kg}^{-1}$ para areia, silte e argila, respectivamente, sendo classificado como de textura muito argilosa. Na caracterização da compactação do solo, utilizou-se um penetrômetro eletrônico marca Falker modelo Penetrolog em que as medidas foram observadas até $550 \mathrm{~mm}$ de profundidade. $\mathrm{O}$ teor de água do solo foi obtido através de amostras na camada de 0 a 150 e 150 a $300 \mathrm{~mm}$, as quais permaneceram em estufa com circulação forçada de ar a uma temperatura de $105^{\circ} \mathrm{C}$ por um período de 24 horas.

A área, em que foram realizados os ensaios, inicialmente foi explorada por seis anos com o cultivo convencional de milho, sendo utilizado em alguns anos 
grade aradora e, em outros, arados de discos para o preparo primário do solo. Após, foi implantada a pastagem de braquiária que permaneceu por mais 8 anos com lotação média de 2 Unidades Animal por hectare. Ao passar 14 anos de exploração do solo, foi implantado o experimento, em que realizou-se uma dessecação, utilizando a dose de $1,920 \mathrm{~kg}$ de Glyfosate por hectare, conforme a indicação do fabricante para a dessecação da braquiária. A área experimental, apresentou $6358 \mathrm{~kg}$ de matéria seca por hectare resultante da pesagem de amostras da parte aérea da pastagem presente após a retirada dos animais da área.

No ensaio se utilizou uma área de $5000 \mathrm{~m}^{2}$, onde foram demarcadas 12 parcelas subdivididas em três blocos, caracterizando um delineamento experimental de blocos casualisados. As parcelas tiveram um comprimento de 10 metros por 7 metros de largura, sendo que a semeadura foi realizada em dois sentidos, visto que se semearam oito linhas espaçadas $700 \mathrm{~mm}$. Assim, se proporcionou maior número de dados, em que se observou a uniformidade dos dados em ambos os sentidos de semeadura, garantindo maior confiabilidade nos resultados obtidos.

Como fonte de tração foi utilizado uma trator Valtra BL 88 4X2 com tração dianteira assistida (TDA) portando um motor modelo VALTRA 420DSR turbo aspirado com 4 cilindros, resultando numa cilindrada de $4400 \mathrm{~cm}^{3}$. O sistema de injeção de combustível se dá através de uma bomba rotativa com injeção direta. Tal motor apresenta uma potência máxima de $65,62 \mathrm{~kW}(88 \mathrm{cv})$ a 2300 rotações por minuto (ISO/NBR 1585). No desenvolvimento dos ensaios utilizaram-se 2000 rotações por minuto em segunda marcha reduzida.

No trator, foram utilizados pneus traseiros 18.4-30R1 e dianteiros 12.4-24R1, com pressão de inflação de $138 \mathrm{kPa}$ (20 psi) e $125 \mathrm{kPa}$ (18 psi) respectivamente. Para lastragem, foram utilizados três pesos de $65 \mathrm{kgf}$ em cada roda traseira e seis pesos de $35 \mathrm{kgf}$ na parte dianteira do trator. Nas rodas traseiras foi utilizado água, ocupando $75 \%$ do volume interno, sendo o restante completado com ar. Para a melhor caracterização do trator realizou-se uma pesagem, que resultou em 43,64 kN (4450 kgf) distribuídos $62 \%$ no eixo traseiro e $38 \%$ no eixo dianteiro.

A fim de caracterizar o combustível utilizado, realizou-se uma análise no laboratório de Química da Faculdade de Engenharia de Varginha na cidade de Varginha - Minas Gerais - que resultou numa massa específica de $0,859 \mathrm{~g} \mathrm{~cm}^{-3}$ a uma temperatura de $20^{\circ} \mathrm{C}$.

$\mathrm{Na}$ semeadura do milho, foi utilizada uma semeadora-adubadora de precisão John Deere RT907 VacuMeter com mecanismo dosador pneumático a vácuo de distribuição de sementes e para a distribuição do fertilizante a semeadora possui mecanismo de rosca sem fim. Buscando maior representatividade no processo de semeadura, foram realizados os testes com os reservatórios, tanto de sementes quando de fertilizantes, com $50 \%$ de sua capacidade máxima. Os quatro módulos de semeadura, espaçados a 700mm, estavam equipados com sulcador tipo disco corta-palha, trabalhando a uma profundidade de 50 $\mathrm{mm}$ no solo. De acordo com os tratamentos, as hastes sulcadoras trabalharam nas seguintes profundidades: Tratamento 1 - $100 \mathrm{~mm}$; Tratamento 2 - $150 \mathrm{~mm}$; Tratamento 3 - $200 \mathrm{~mm}$; Tratamento 4 - $250 \mathrm{~mm}$. A alteração desse parâmetro de trabalho foi possível devido a regulagem de furos existente no acoplamento da haste na semeadora e alterações na pressão da mola. Para a incorporação da semente; a semeadora-adubadora estava dotada de disco duplo defasado com rodas reguladoras de profundidade nas suas laterais.

Para o calculo do índice de patinagem, considerouse o tempo decorrido para que o trator percorresse o trajeto da parcela sem a semeadora acoplada e, posteriormente, com a semeadora acoplada realizando a semeadura. Assim, os cálculos do índice de patinagem foram realizados de acordo com a Equação 1.

$P \%=\left(\frac{\left(t_{1}-t_{0}\right)}{t_{0}}\right) \times 100$

em que:

$\mathrm{P}_{\%}=$ índice de patinagen;

$\mathrm{t}_{1}=$ tempo com carregamento;

$\mathrm{t}_{0}=$ tempo sem carregamento.

A quantificação da força na barra de tração foi obtida com o auxílio de uma célula de carga marca Kyowa, modelo LOAD CELL, série n. CA 3125 que ficou posicionada entre a barra de tração do trator e o engate do cabeçalho da semeadora-adubadora. A célula de carga foi interligada ao sistema de aquisição de dados (Data Collector), que recebeu os sinais em $\mathrm{mV}$ e armazenou em disquetes para posterior passagem de dados a um computador. Os dados armazenados foram transformados para kN utilizando-se uma curva de calibração de acordo com a Equação 02 resultante da calibração da célula de carga utilizando-se uma máquina de ensaio universal.

$$
y=1928,7 x+71,102
$$


em que:

$\mathrm{y}=$ Força em kgf;

$\mathrm{x}=$ valores em $\mathrm{mV}$ obtidos no DataCollector.

Para a análise do consumo de combustível do trator, foi instalado um fluxômetro eletromecânico de forma que contabilizasse apenas o diesel consumido. O fluxômetro foi conectado a um processador de fluxo digital que expressa o consumo em tempo real num display digital. Por isso, houve a necessidade de filmagem do display para o armazenamento dos dados de cada parcela. Para o cálculo do consumo específico de combustível por unidade de potência na barra de tração foi utilizada a Equação 3.

$$
C e c=\frac{C h * \delta}{P b}
$$

em que:

Cec $=$ consumo específico $\mathrm{em} \mathrm{g} \mathrm{kW} \mathrm{h}^{-1}$;

$C h=$ consumo horário com base em volume em $\mathrm{L} \mathrm{h}^{-1}$;

$\delta=$ densidade do combustível em g L${ }^{-1}\left(0,859 \mathrm{~g} \mathrm{~L}^{-1}\right)$;

$P b=$ potência na barra de tração em $\mathrm{kW}$.

A capacidade de campo teórica média foi determinada em função das diferentes profundidades de trabalho das hastes sulcadoras e pela largura da faixa trabalhada, conforme a Equação 4.

$$
C c t=\frac{V^{*} L}{10}
$$

em que:

$\mathrm{Cct}=$ capacidade de campo teórica, em ha $\mathrm{h}^{-1}$;

$\mathrm{V}=$ velocidade de deslocamento do conjunto corrigida pela patinagem, em $\mathrm{km} \mathrm{h}^{-1}$;

$\mathrm{L}=$ largura da faixa trabalhada pelo conjunto $\mathrm{em} \mathrm{m}$.

\section{RESULTADOS E DISCUSSÃO}

Os resultados da resistência à penetração do solo foram semelhantes aos citados por Conte et al. (2007) e Lanzanova et al. (2007). Observa-se na Figura 1 que os dados relativos a resistência mecânica do solo à penetração caracterizaram um solo sob pastejo animal, sendo que os maiores picos $(2480 \mathrm{Mpa})$ da resistência à penetração ocorreram nas camadas até $150 \mathrm{~mm}$ de profundidade. Assim, destaca-se a haste sulcadora que trabalhou, na profundidade de $250 \mathrm{~mm}$, rompendo a camada que oferece limitação no desenvolvimento do sistema radicular da cultura do milho.

O solo da área experimental apresentou umidade gravimétrica média, no momento da semeadura, de
$0,3684 \mathrm{~kg} \mathrm{~kg}^{-1}$ com desvio padrão de $2,50 \%$ entre as amostras coletadas, em duas profundidades (0-150 mm e 150-300 mm), em cada unidade experimental, não diferenciando-se, estatisticamente, os valores de uma camada em relação a outra.

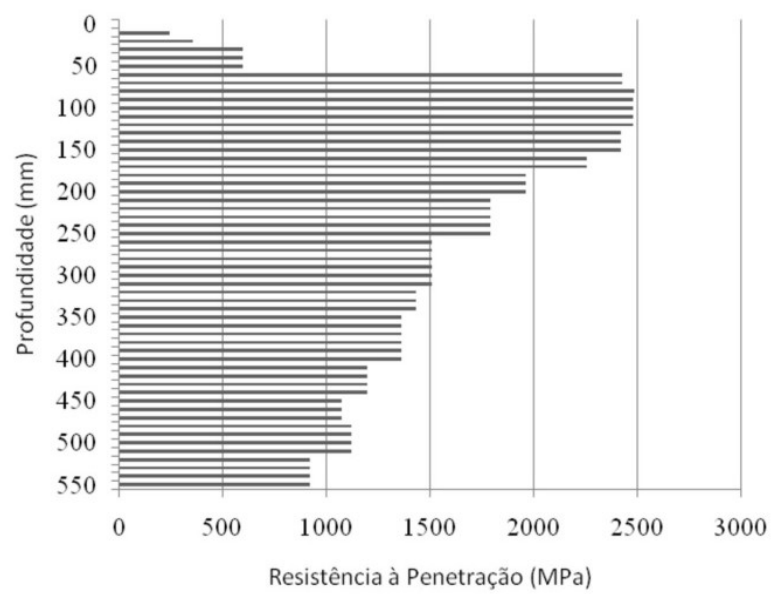

Figura 1 - Representação gráfica da resistência média à penetração do solo.

Analisando os dados da Tabela 1, observa-se que o consumo horário de combustível foi menor quando a haste sulcadora trabalhou na profundidade de $100 \mathrm{~mm}$. À medida que se teve o aumento na profundidade da haste, verificase que as profundidades 150 e $200 \mathrm{~mm}$ não apresentaram diferenças estatísticas, aumentando o consumo 7,45 e 6,68 $\%$ respectivamente em relação a profundidade de $100 \mathrm{~mm}$. Já na maior profundidade houve um maior consumo com acréscimo de $13,52 \%$ quando comparado com a profundidade anterior de $200 \mathrm{~mm}$. Destaca-se que o consumo do trator, sem a aplicação de nenhum tipo de carga a 2000 rotações por minuto, foi de $9,32 \mathrm{~L} \mathrm{~h}^{-1}$.

A força de tração, conforme apresentado na Tabela 1, teve variação estatística em todas as profundidades, sendo que a menor demanda de força foi observada na menor profundidade. Já a profundidade de $150 \mathrm{~mm}$ mostra um acréscimo na força de tração de $61,90 \%$ em relação ao Tratamento 1. No entanto, quando a haste sulcadora trabalhou na profundidade de $200 \mathrm{~mm}$, se teve um decréscimo na demanda de força $4,84 \%$ em relação ao Tratamento 2. Isso pode ser explicado na Figura 1, em que se observa maior resistência mecânica do solo à penetração até os $150 \mathrm{~mm}$ de profundidade, onde a ponteira da haste sulcadora encontra maior resistência de ruptura do solo. À medida que a haste trabalhou abaixo dessa camada mais 
compactada, embora com maior área de contato ferramentasolo, a geometria da haste (ângulo de ataque) pode ter colaborado para essa menor demanda na força de tração.

Veruschka et al. (2006), ao trabalhar com uma semeadora-adubadora de semeadura direta em diferentes níveis de compactação na camada de 0 a 100 mm, em que obteve diferenças significativas na força de tração da haste sulcadora, quando esse mecanismo sulcador estava trabalhando ligeiramente abaixo, numa profundidade de $125 \mathrm{~mm}$. Dessa forma, observa-se, que quando a ponteira da haste sulcadora trabalha nas camadas mais resistentes, se tem maior demanda de força de tração do que ao trabalhar com a ponteira ligeiramente abaixo dessas camadas que oferecem maior resistência mecânica do solo a penetração. Explica-se esse fator, devido ao ângulo de ataque que o mecanismo sulcador tem em relação ao solo.

$\mathrm{Na}$ maior profundidade de trabalho da haste sulcadora (Tratamento 4), obteve-se um aumento de 13,62\% na demanda de força de tração em relação a profundidade de $200 \mathrm{~mm}$.
A patinagem das rodas motrizes do trator variou com as diferentes profundidades de atuação dos sulcadores da semeadora, conforme pode ser verificado na Tabela 1 . Na condição profundidade de $200 \mathrm{~mm}$, pode-se observar uma diminuição do índice de patinagem e força na barra de tração com relação a profundidade de $150 \mathrm{~mm}$ o que é explicado pela diminuição da resistência mecânica do solo à penetração nesta camada. Porém, na condição em que a haste sulcadora atuou a $250 \mathrm{~mm}$ de profundidade, houve um novo acréscimo na patinagem o que resultou num aumento da força na barra de tração e no consumo de combustível.

$\mathrm{Na}$ Tabela 2, observa-se que a demanda de potência na barra de tração foi menor para a profundidade de 100 mm em relação às demais profundidades, que por sua vez, não diferiram entre si. $\mathrm{O}$ parâmetro potência na barra é função da força na barra de tração e da velocidade operacional (Salvador et al., 2009).

O consumo específico de combustível apresentouse igual nas profundidades de 150 e $200 \mathrm{~mm}$, tendo o maior consumo específico na menor profundidade, seguido pela maior profundidade da haste sulcadora.

Tabela 1 - Consumo de Combustível $\left(\mathrm{L} \mathrm{h}^{-1}\right)$, Força de Tração $(\mathrm{kN})$ e o Índice de Patinagem $(\%)$ em relação as diferentes profundidades.

\begin{tabular}{cccc}
\hline Tratamentos & Consumo & Força de Tração & Índice de Patinagem \\
\hline $100 \mathrm{~mm}$ & $10,75 \mathrm{c}$ & $19,19 \mathrm{~d}$ & $10,41 \mathrm{~d}$ \\
$150 \mathrm{~mm}$ & $11,55 \mathrm{~b}$ & $31,08 \mathrm{~b}$ & $25,29 \mathrm{~b}$ \\
$200 \mathrm{~mm}$ & $11,47 \mathrm{~b}$ & $29,57 \mathrm{c}$ & $19,81 \mathrm{c}$ \\
$250 \mathrm{~mm}$ & $12,20 \mathrm{a}$ & $33,60 \mathrm{a}$ & $38,21 \mathrm{a}$ \\
\hline Média Geral & 11,49 & 28,36 & 23,43 \\
\hline CV $(\%)$ & 0,86 & 0,780 & 10,23 \\
\hline
\end{tabular}

As médias seguidas pela mesma letra não diferem estatisticamente entre si. Foi plicado o Teste de Tukey ao nível de 5\% de probabilidade.

Tabela 02 - Potência na Barra de Tração (kW), Consumo Específico de Combustível ( $\left.\mathrm{g} \mathrm{kW} \mathrm{h}^{-1}\right)$ e Capacidade de Campo Teórica $\left(\right.$ ha h $\left.^{-1}\right)$.

\begin{tabular}{cccc}
\hline Tratamentos & Potência na Barra de Tração & $\begin{array}{c}\text { Consumo Específico de } \\
\text { Combustível }\end{array}$ & $\begin{array}{c}\text { Capacidade de Campo } \\
\text { Teórica }\end{array}$ \\
\hline $100 \mathrm{~mm}$ & $20,57 \mathrm{~b}$ & $449 \mathrm{a}$ & $1,07 \mathrm{a}$ \\
$150 \mathrm{~mm}$ & $29,35 \mathrm{a}$ & $338 \mathrm{c}$ & $0,94 \mathrm{c}$ \\
$200 \mathrm{~mm}$ & $29,21 \mathrm{a}$ & $337 \mathrm{c}$ & $0,99 \mathrm{~b}$ \\
$250 \mathrm{~mm}$ & $28,78 \mathrm{a}$ & $364 \mathrm{~b}$ & $0,86 \mathrm{~d}$ \\
\hline Média Geral & 26,98 & 372 & 0,97 \\
\hline CV $(\%)$ & 1,86 & 2,02 & 1,11 \\
\hline
\end{tabular}

As médias seguidas pela mesma letra não diferem estatisticamente entre si. Foi plicado o Teste de Tukey ao nível de 5\% de probabilidade. 
A maior capacidade de campo teórica ocorreu para a profundidade de $100 \mathrm{~mm}$, enquanto que a menor foi para a profundidade de $250 \mathrm{~mm}$. Comparando-se as profundidades de 150 e $200 \mathrm{~mm}$, houve uma redução na capacidade de campo teórica para a profundidade de 150 mm, provavelmente devido à maior reistência mecânica do solo à penetração dessa camada.

Elaborando-se uma curva de linha de tendência logarítmica de $3^{\mathrm{a}}$ ordem, relacionando a potência na barra de tração e o índice de patinagem, obteve-se um $\mathrm{R}^{2}$ igual a 0,938 (Figura 2). Tais resultados estão de acordo com os de Corrêa et al. (1995), analisando que a potência na barra de tração tende a aumentar conforme a patinagem até atingir um nível máximo de potência na barra, a qual posteriormente diminui com o aumento da patinagem.

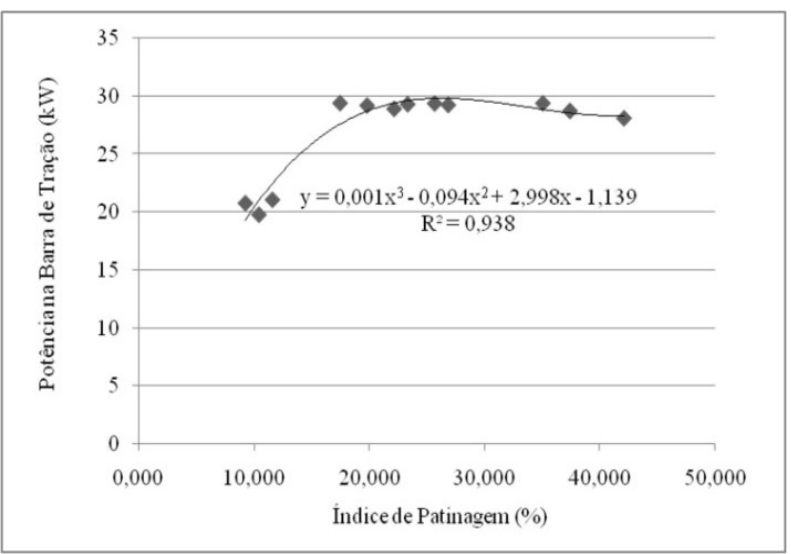

Figura 2 - Linha de tendência logarítma entre o índice de patinagem e a força de tração.

\section{CONCLUSÕES}

Em solos compactados pelo pisoteio dos bovinos, o aumento da profundidade de trabalho das hastes sulcadoras resulta em acréscimo na força de tração da semeadora-adubadora e, no trator agrícola, ocorre aumento do índice de patinagem e do consumo de combustível.

A força de tração e o índice de patinagem diminuem quando as ponteiras das hastes sulcadoras atuam ligeiramente abaixo $(50 \mathrm{~mm})$ das camadas superficiais de solo com maior resistência mecânica a penetração.

Portanto, na integração Lavoura-Pecuária é importante o conhecimento da resistência mecânica do solo a penetração para a correta regulagem da profundidade de trabalho das hastes sulcadoras, logo abaixo das camadas mais resistentes do solo, afim de otimizar a operação do conjunto trator-semeadora e proporcionar um ambiente mais favorável ao desenvolvimento do sistema radicular da cultura do milho.

\section{AGRADECIMENTOS}

À Fundação de Amparo à Pesquisa do Estado de Minas Gerais - FAPEMIG - e `a Universidade Federal de Lavras - UFLA.

\section{REFERÊNCIAS BIBLIOGRÁFICAS}

AMARAL, A.S.; SLOMP, E.P.; PICCOLI, C.; PALMA, M.A.Z.; ORO, A.S. Utilização de gesso agrícola no sistema plantio-direto. Perspectiva, Erechim, v.30, p.111-124, 2006.

CONTE, O.; LEVIEN, R.; TREIN, C.R.; CEPIK, C.T.C.; DEBIASI, H. Demanda de tração em haste sulcadora na integração lavoura-pecuária com diferentes pressões de pastejo e sula relação com o estado de compactação do solo. Engenharia Agrícola, Jaboticabal, v.27, n.1, p.220228, jan./abr. 2007.

CORREA, I.M.; MILAN, M.; RIPOLLI, T.C.; MAZIERO, J.V.G.; YANAI, K.; MENEZES, J.F. Pneu radial e diagonal: desempenho de tração em um trator com tração dianteira auxiliar. Engenharia Agrícola, Campinas, v.15, p.45-59, 1995.

\section{EMPRESA BRASILEIRA DE PESQUISA}

AGROPECUÁRIA. Centro Nacional de Pesquisa de Solos. Sistema brasileiro de classificação de solos. Rio de Janeiro, 1999. 412p.

\section{EMPRESA BRASILEIRA DE PESQUISA}

AGROPECUÁRIA. Centro Nacional de Pesquisa de Solos. Sistema brasileiro de classificação de solos. 2.ed. Rio de Janeiro, 2006. 306p.

FERNANDES, H.C.; SILVEIRA, J.C. da; RINALDI, C.N. Avaliação do custo energético de diferentes operações agrícolas mecanizadas. Ciência e Agrotecnologia, Lavras, v.32, n.5, p.1582-1587, set./out. 2008.

FOLONI, J.S.S.; CALONEGO, J.C.; LIMA, S.L. Efeito da compactação do solo no desenvolvimento aéreo e radicular de cultivares de milho. Pesquisa Agropecuária Brasileira, Brasília, v.38, n.8, p.947-953, ago. 2003.

\section{INSTITUTO AGRONÔMICO DE CAMPINAS. Plantio direto: caminho para a agricultura sustentável. Campinas, 2009. Disponível em: <http:// iwww.iac.sp.gov.br/Tecnologias/PlantioDireto PlantioDireto.htm, Acesso em: 27 ago. 2009.}


KLUTHCOUSKI, J.; STONE, L.F.; AIDAR, H. Integração lavoura-pecuária. Goiânia: Embrapa Arroz e Feijão, 2003. 570p.

LANZANOVA, M.E.; NICOLOSO, R.S.; LOVATO, T.; ELTZ, F.L.F.; AMADO, T.J.C.; REINERT, D.J.

Atributos físicos do solo em sistema de integração lavoura-pecuária sob plantio direto. Revista

Brasileira de Ciência do Solo, Viçosa, v.31, n.5, p.1131-1140, 2007.

MION, R.L.; BENEZ, S.H. Esforços em ferramentas rompedoras de solo de semeadoras de plantio direto.

Ciência e Agrotecnologia, Lavras, v.32, n.5, p.1594-1600, set./out. 2008.

REINERT, D.J.; REICHERT, J.M.; AITA, C.; ALBUQUERQUE, J.A.; ANDRADA, C. Limites críticos de densidade do solo para o crescimento de raízes de cobertura em argissolo vermelho. Revista Brasileira de Ciência do Solo, Viçosa, v.32, n.5, set./out. 2008.

SALVADOR, N.; MION, R.L.; BENEZ, S.H. Consumo de combustível em diferentes sistemas de preparo periódico realizados antes e depois da operação de subsolagem. Ciência e Agrotecnologia, Lavras, v.33, n.3, maio/jun. 2009.
SANTOS, A.P.; VOLPATO, C.E.S.; TOURINO, M.C.C. Desempenho de três semeadoras-adubadoras de plantio direto para a cultura do milho. Ciência e Agrotecnologia, Lavras, v.32, n.2, p.540-546, mar./abr. 2008.

SILVA, P.R.A.; BENEZ, S.H. Avaliação de forças resultantes de mecanismos sulcadores de semeadorasadubadoras de plantio direto. Energia na Agricultura, Botucatu, v.20, n.2, p.76-82, 2005.

STONE, L.F.; SILVEIRA, P.M. da. Efeitos do sistema de preparo na compactação do solo, disponibilidade hídrica e comportamento do feijoeiro. Pesquisa Agropecuária Brasileira, Brasília, v.34, n.1, p.83-91, jan. 1999.

STRECK, C.A.; REICHERT, J.M.; REINERT, D.J.; KAISER, D.R. Modificações em propriedades físicas com a compactação do solo causada pelo tráfego induzido de um trator em plantio direto. Ciência Rural, Santa Maria, v.34, n.3, p.755-760, maio/jun. 2004.

VERUSCHKA, R.M.; ANDREOLLA, A.; GABRIEL FILHO, A. Demanda de potência de uma semeadura com dois tipos de sulcadores em áreas compactadas pelo pisoteio de animais no sistema de integração lavourapecuária. Engenharia Agrícola, Jaboticabal, v.26, n.3, p.768-776, set./dez. 2006. 